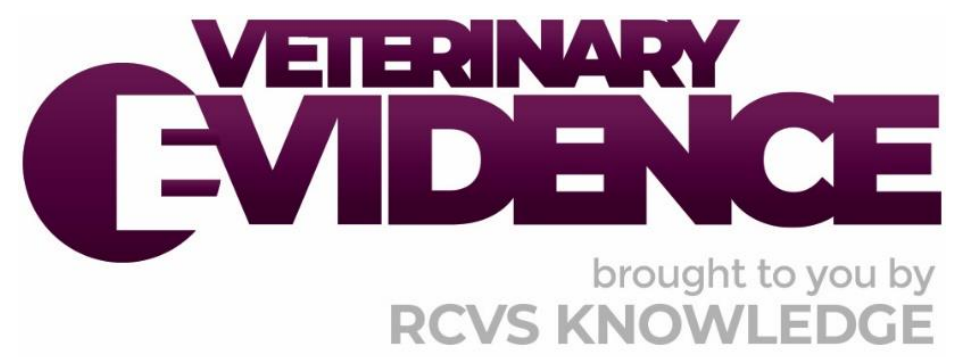

\title{
For horses undergoing general anaesthesia, are rope recoveries or free recoveries better?
}

\section{A Knowledge Summary by}

Ffion Lloyd BVSc MRCVS ${ }^{1 *}$

Pamela Murison BVMS PhD DipECVAA DVA PGCert(HE) FHEA MRCVS ${ }^{1}$

\footnotetext{
1 University of Glasgow Small Animal Hospital, 464 Bearsden Rd, Bearsden, Glasgow G61 1BD

* Corresponding Author (f.lloyd.1@research.gla.ac.uk)
}

ISSN: 2396-9776

Published: 30 Sep 2021

in: The Veterinary Evidence journal Vol 6, Issue 3

DOI: https://doi.org/10.18849/ve.v6i3.451

Reviewed by: Mark Senior (BVSc PhD SFHEA CertVA DipECVAA MRCVS) and Kate Walters (MA VetMB AFHEA MRCVS)

Next Review Date: 14 Apr 2023 


\section{KNOWLEDGE SUMMARY}

\section{PICO question}

In horses undergoing general anaesthesia, does assistance with ropes result in better recoveries when compared to no assistance ('free' recovery)?

\section{Clinical bottom line}

\section{Category of research question}

Treatment

\section{The number and type of study designs reviewed}

One randomised, non-blinded controlled trial and two retrospective cohort studies

\section{Strength of evidence}

Weak

\section{Outcomes reported}

The three studies reviewed arrive at different conclusions regarding the utility of rope assistance in recovery from general anaesthesia in horses, but examine very different populations. The randomised controlled trial provides weak evidence that rope assistance can shorten recovery and improve recovery quality in healthy (American Society of Anesthesiologists (ASA) I-II) horses. One retrospective cohort study provides weak evidence that rope assistance confers a reduction in fatality in both healthy and sick horses. The other retrospective cohort study provides weak evidence that rope assistance confers no benefit to horses undergoing emergency colic surgery. Both assisted and unassisted groups in each study had fatalities and all studies reported complications related to the rope recovery system

\section{Conclusion}

Insufficient evidence is available to permit a full recommendation regarding rope assistance during recovery from general anaesthesia in horses. Rope assistance may improve recovery time and quality in some horses. The decision to perform a rope-assisted recovery must be made considering individual patient, team and clinic factors. Rope assistance cannot prevent fatalities in recovery

\section{$\underline{\text { How to apply this evidence in practice }}$}

The application of evidence into practice should take into account multiple factors, not limited to: individual clinical expertise, patient's circumstances and owners' values, country, location or clinic where you work, the individual case in front of you, the availability of therapies and resources.

Knowledge Summaries are a resource to help reinforce or inform decision making. They do not override the responsibility or judgement of the practitioner to do what is best for the animal in their care. 


\section{The evidence}

Only three studies were found that address the PICO question directly by comparing rope-assisted and unassisted recoveries in horses, thereby comprising a limited evidence base for this clinical question. Of these studies, one is a single-centre randomised controlled trial (Arndt et al., 2020) involving 301 horses, representing the highest level in the hierarchy of evidence; the others are single-centre retrospective analyses of case records from 200 horses (Rüegg et al., 2016) and 1252 horses (Nicolaisen et al., 2020) (hereafter referred to as the 'three identified studies'). The difference in population size in Nicolaisen et al. (2020) and Rüegg et al. (2016) (1252 horses versus 200 horses respectively) lends Nicolaisen et al. (2020) a higher evidential status, and so it could be argued that its results are more valid. Thus the 'weighting' of the studies in terms of consideration of results would therefore be first, second and third for Arndt et al. (2020), Nicolaisen et al. (2020) and Rüegg et al. (2016).

Auer \& Huber's 2012 study presented as an abstract at a conference directly addresses the PICO question in addition to the three identified studies. It compares rope-assisted recoveries with unassisted recoveries in a cohort containing both elective and emergency cases. A lack of any demonstrable benefit of rope assistance for any sub-group of horses was reported, and the unassisted group recovered significantly faster. However, only brief details are described and therefore the study cannot be critically appraised.

Each of the three identified studies were conducted at different institutions. The nature of the populations in each study vary considerably; the Arndt et al. (2020) cohort was comprised of healthy horses, ASA grade I or II, undergoing a variety of elective surgical procedures. In contrast, Rüegg et al. (2016) examines a population of horses that presented for emergency colic surgery that may be in a critical clinical condition; Nicolaisen et al. (2020) includes horses presenting for both elective and emergency procedures. Significant differences in perianaesthetic morbidity and mortality, and crucially, recovery, between the study populations can therefore be expected. The rope systems examined in each study are similar in description (head and tail ropes passed through rings attached to the wall and controlled by two people), but are not depicted, making detailed comparison difficult. Arndt et al. (2020) and Rüegg et al. (2016) excluded horses weighing under $200 \mathrm{~kg}$, perhaps reflecting the opinion that lighter horses do not require this type of assistance in recovery. Nicolaisen et al. (2020) excluded horses under 1 year of age, possibly because this cohort may be smaller and/or less likely to be accustomed to handling and headcollars.

\section{Summary of the evidence}

\begin{tabular}{|c|c|}
\hline \multicolumn{2}{|l|}{ Arndt et al. (2020) } \\
\hline $\begin{array}{l}\text { Population: } \\
\end{array}$ & $\begin{array}{l}\text { Healthy adult horses (client-owned) undergoing general anaesthesia } \\
\text { for elective surgical procedures presented to one private equine } \\
\text { hospital. } \\
\text { - ASA I or II. } \\
\text { - Aged 1-23 years (mean } \pm \text { SD: } 6.6 \pm 4.5 \text { years). } \\
\text { - Estimated body weight }>200 \mathrm{~kg} \text { (mean } \pm \text { SD: } 517 \pm 100 \mathrm{~kg} \text { ). } \\
\text { - Majority warmbloods. } \\
\text { - General anaesthesia (GA) time (mean } \pm \text { SD): } 70 \pm 29 \\
\text { minutes. }\end{array}$ \\
\hline Sample size: & 301 horses (305 recoveries) \\
\hline Intervention details: & $\begin{array}{l}\text { - Horses randomly allocated to recover from general } \\
\text { anaesthesia with head-and-tail rope assistance or without } \\
\text { assistance. } \\
\text { - Sedation for intravenous (IV) catheter placement: } \\
\text { detomidine } 10-30 \mu \mathrm{g} / \mathrm{kg} \text { IV. }\end{array}$ \\
\hline
\end{tabular}




\begin{tabular}{|c|c|}
\hline & 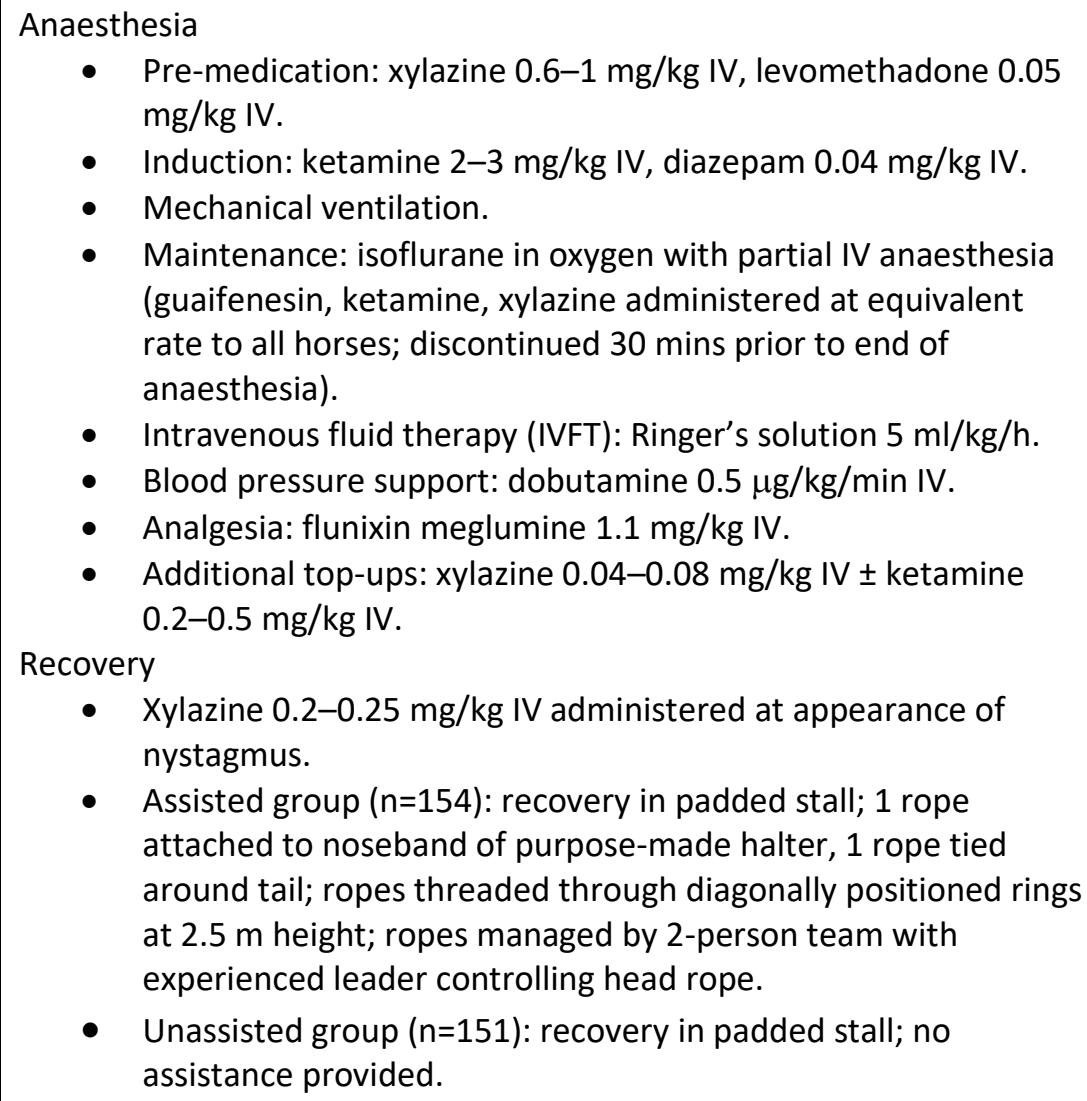 \\
\hline Study design: & Randomised, prospective, non-blinded clinical trial \\
\hline Outcome studied: & $\begin{array}{l}\text { Both objective and subjective assessment carried out for both groups. } \\
\text { Objective: } \\
\text { - Time from end of GA to first activity (head/leg movement). } \\
\text { - Time from end of GA to sternal recumbency. } \\
\text { - Duration of sternal recumbency. } \\
\text { - Time from end of GA to first standing attempt. } \\
\text { - Time from end of GA to 'safe stand' (standing steadily with } \\
\text { - Number of standing attempts. } \\
\text { - Number and type of recovery-associated injuries. } \\
\text { Subjective: } \\
\text { - Quality of recovery: composite scoring system ranging from } 11 \\
\text { (best recovery) to } 100 \text { (worst recovery); scoring performed by } \\
\text { same person (experienced person controlling head rope in } \\
\text { assisted group). }\end{array}$ \\
\hline $\begin{array}{l}\text { Main findings: } \\
\text { (relevant to PICO question): }\end{array}$ & $\begin{array}{l}\text { - Horses in assisted group made fewer attempts to stand: } \\
\text { (median) } 1 \text { attempt versus (median) } 3 \text { attempts in unassisted } \\
\text { group. } \\
\text { - } \\
\text { Duration of recovery was shorter in assisted group: (mean) } 36 \\
\text { minutes versus (mean) } 41 \text { minutes in unassisted group. } \\
\text { Quality of recovery was better in assisted group: (mean) } 28 \\
\text { points versus (mean) } 38 \text { points in unassisted group. } \\
\text { - Recovery-associated injuries were lower in assisted group: } \\
\text { (total) } 2 \text { horses versus (total) } 9 \text { horses in unassisted group. } \\
\text { - Euthanasia occurred in } 1 \text { horse in each group. }\end{array}$ \\
\hline
\end{tabular}




\begin{tabular}{|c|c|}
\hline Limitations: & $\begin{array}{l}\text { - Despite similar anaesthesia protocols, dose rates differed } \\
\text { according to clinical judgement of anaesthetist - could affect } \\
\text { recovery quality and/or recovery timings between horses. } \\
\text { - Partial IV anaesthesia administered through giving set via } \\
\text { drops per second - subjectivity and inaccuracy possible with } \\
\text { this method; could cause variation in actual dose } \\
\text { administered between horses. } \\
\text { - Estimated body weights used: could cause discrepancies in } \\
\text { actual doses of anaesthetic agents given between horses. } \\
\text { - Insufficient detail provided regarding perianaesthetic } \\
\text { monitoring (e.g unclear if invasive blood pressure and } \\
\text { arterial blood gasses were measured) - hypotension, } \\
\text { hypoxaemia etc. could have occurred and affected recovery } \\
\text { quality/timings; incidence of these events were not } \\
\text { reported. } \\
\text { - Recovery quality scoring performed by single observer only. } \\
\text { Recovery quality scoring performed by person actively } \\
\text { involved in assisted recoveries: reliance on memory of } \\
\text { person to assign scores could affect accuracy of scores given. } \\
\text { - Recovery scoring system not validated. } \\
\text { Recovery score results reported using mean: recovery score } \\
\text { is a form of ordinal (i.e not continuous) data; controversy } \\
\text { exists regarding the appropriateness of presenting this type } \\
\text { of data as mean (may be more correct to report results as } \\
\text { median). }\end{array}$ \\
\hline
\end{tabular}

Rüegg et al. (2016)

\begin{tabular}{|c|c|}
\hline Population: & $\begin{array}{l}\text { Horses (client-owned) undergoing emergency abdominal (colic) } \\
\text { surgery presented to one university equine hospital. } \\
\text { - }>200 \mathrm{~kg} \text {. } \\
\text { - No general anaesthesia in previous } 12 \text { months. } \\
\text { - Age (mean } \pm \mathrm{SD} \text { ): } 13.3 \pm 6 \text { years. } \\
\text { - Majority warmbloods. } \\
\text { - Median GA time: assisted group } 212 \text { minutes, unassisted } \\
\text { group } 205 \text { minutes. }\end{array}$ \\
\hline Sample size: & 200 horses \\
\hline Intervention details: & $\begin{array}{l}\text { - Retrospective analysis of recoveries from emergency colic } \\
\text { surgery. } \\
\text { Two groups: assisted with head-and-tail ropes (100 horses) } \\
\text { and unassisted (100 horses); groups defined by hospital } \\
\text { policy change from unassisted to assisted recovery in } 2012 \text {. } \\
\text { Similar anaesthesia protocol for all horses: } \\
\text { - Sedation to permit clinical examination/handling if } \\
\text { necessary (separate to anaesthetic premedication): Xylazine } \\
0.2-1.1 \mathrm{mg} / \mathrm{kg} \text { intravenously (IV) or detomidine } 0.01-0.02 \\
\mathrm{mg} / \mathrm{kg} \mathrm{IV} \pm \text { butorphanol } 0.05-0.1 \mathrm{mg} / \mathrm{kg} \mathrm{IV} \text {. } \\
\text { - Flunixin meglumine } 1.1 \mathrm{mg} / \mathrm{kg} \mathrm{IV} \text {, vitamin E } 1 \mathrm{mg} / \mathrm{kg} \\
\text { intramuscularly (IM), selenium } 0.04 \mathrm{mg} / \mathrm{kg} \mathrm{IM} \text {, hetastarch } \\
\text { 10\% 5-7 ml/kg IV, lactated ringer's solution } 10-20 \mathrm{ml} / \mathrm{kg} \mathrm{IV} \\
\text { prior to anaesthesia. }\end{array}$ \\
\hline
\end{tabular}




\begin{tabular}{|c|c|}
\hline & 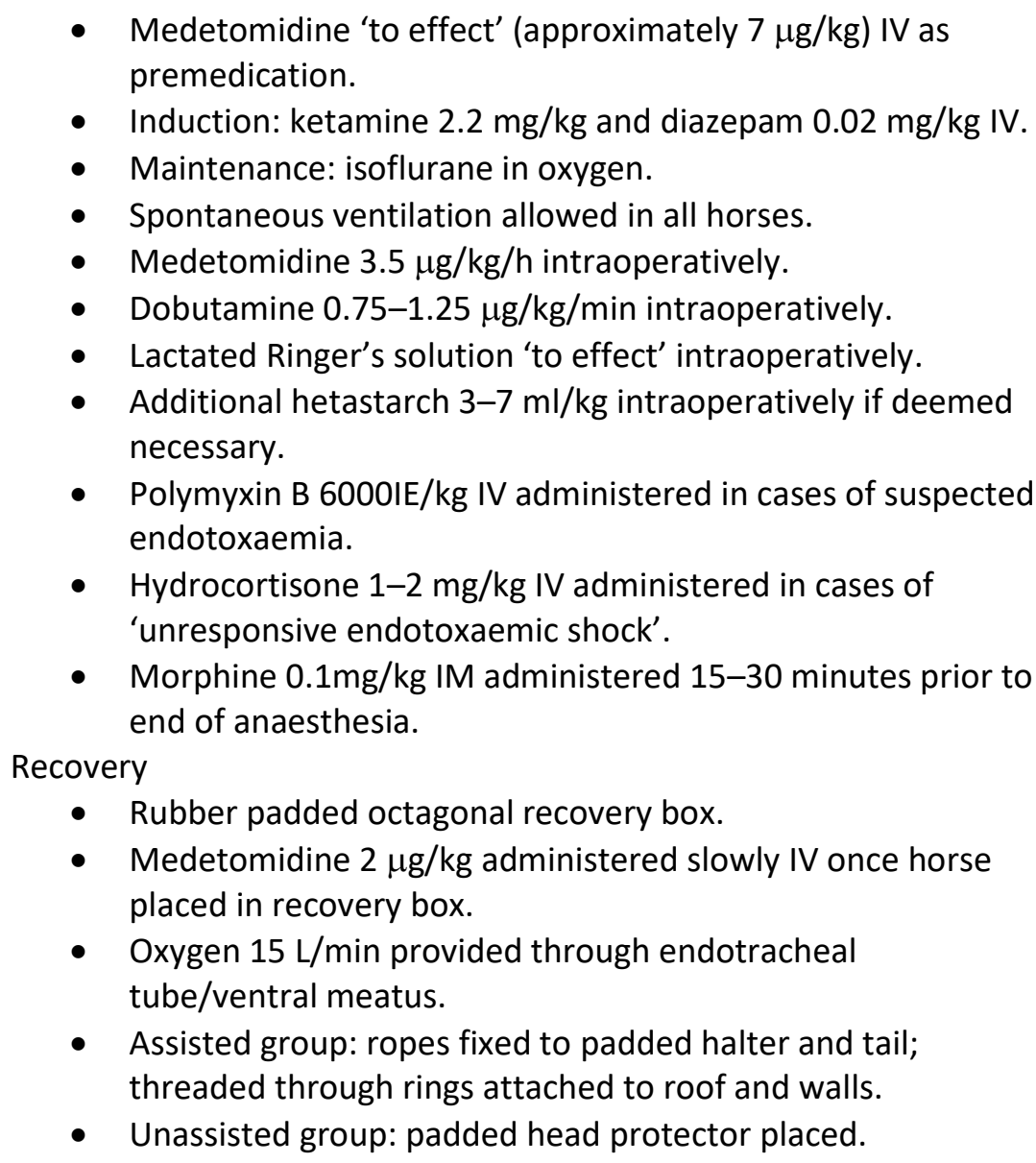 \\
\hline Study design: & Retrospective comparative analysis \\
\hline Outcome studied: & $\begin{array}{l}\text { Both objective and subjective assessment carried out for both } \\
\text { groups. } \\
\text { Objective } \\
\text { - Signalment data (age, body weight, breed, sex). } \\
\text { - Total anaesthesia time. } \\
\text { - Incidence of hypotension (= mean arterial pressure (MAP) } \\
\text { - In mmHg for } \geq 15 \text { minutes). } \\
\text { - Time from end of anaesthesia to sternal recumbency. } \\
\text { - Time from end of anaesthesia to standing. } \\
\text { Subjective } \\
\text { - Recovery score: simple descriptive scale; } 1 \text { = best recovery, } 5 \\
\text { - Scoring performed by anaesthetist in charge of case. } \\
\text { - Recoveries in assisted group additionally scored by single } \\
\text { observer viewing video recordings using same scale. }\end{array}$ \\
\hline $\begin{array}{l}\text { Main findings: } \\
\text { (relevant to PICO question): }\end{array}$ & $\begin{array}{l}\text { - No difference in signalment of horses between assisted and } \\
\text { unassisted groups. } \\
\text { - No difference in duration of anaesthesia between assisted } \\
\text { and unassisted groups. } \\
\text { - No difference in type of colic surgery performed between } \\
\text { assisted and unassisted groups. }\end{array}$ \\
\hline
\end{tabular}




\begin{tabular}{|c|c|}
\hline & $\begin{array}{l}\text { - No difference in incidence of hypotension or hypoxaemia } \\
\text { between assisted and unassisted groups. } \\
\text { - No difference in recovery scores between assisted and } \\
\text { unassisted groups. } \\
\text { - } \text { No difference in time to sternal recumbency or standing } \\
\text { between assisted and unassisted groups. } \\
\text { Three horses in each group died or were euthanised; two in } \\
\text { the assisted group due to recovery-related injuries and one } \\
\text { in the unassisted group due to recovery-related injuries. } \\
\text { - Rope-related complications included: failure of halter ring in } \\
\text { one horse resulting in suspected cervical dislocation, } \\
\text { detachment of head rope in one horse, halter detachment in } \\
\text { three horses, twisting of ropes resulting in release and re- } \\
\text { attachment in nine horses, wrapping of rope around legs in } \\
\text { one horse. } \\
\text { Hypoxaemia during anaesthesia was significantly associated } \\
\text { with 'non-safe' recoveries (= recovery score } \geq 4 \text { ). }\end{array}$ \\
\hline Limitations: & $\begin{array}{l}\text { - Anaesthesia protocol similar but not identical between } \\
\text { horses: variation in drugs, dosages and timings of } \\
\text { administration could affect recovery quality and time. } \\
\text { - Rope assistance (in assisted group) performed by different } \\
\text { personnel: varying degrees of experience could affect } \\
\text { recovery quality and incidence of injuries. } \\
\text { - Hospital policy change provided delineation between } \\
\text { assisted and unassisted group: improvement or variation in } \\
\text { facilities/equipment in hospital and knowledge/experience } \\
\text { of anaesthesia team between two time periods could } \\
\text { confound recovery results. } \\
\text { Simplistic recovery scoring scale reduces 'sensitivity' of score } \\
\text { and its ability to reflect differences in recoveries. }\end{array}$ \\
\hline
\end{tabular}

Nicolaisen et al. (2020)

\begin{tabular}{|c|c|}
\hline Population: & $\begin{array}{l}\text { Horses (client-owned) }>1 \text { year old undergoing general anaesthesia } \\
\text { for any type of surgery presented to one university equine hospital. }\end{array}$ \\
\hline Sample size: & 1252 horses \\
\hline Intervention details: & $\begin{array}{l}\text { - Retrospective analysis of recoveries from emergency and } \\
\text { elective surgeries. } \\
\text { - Two groups: assisted with head-and-tail ropes ( } 662 \text { horses) } \\
\text { and unassisted ( } 590 \text { horses); groups defined by hospital } \\
\text { policy change from unassisted to assisted recovery in } \\
\text { October } 2014 \text {. } \\
\text { Anaesthesia protocol not standardised: } \\
\text { - Acepromazine } 0.03 \mathrm{mg} / \mathrm{kg} \mathrm{IV} \mathrm{for} \mathrm{all} \mathrm{horses.} \\
\text { - Detomidine } 0.01 \mathrm{mg} / \mathrm{kg} \mathrm{IV} \mathrm{and/or} \mathrm{romifidine} 0.06 \mathrm{mg} / \mathrm{kg} \mathrm{IV} \\
\text { and/or xylazine } 0.15-0.2 \mathrm{mg} / \mathrm{kg} \text { IV together with } \\
\text { butorphanol } 0.03 \mathrm{mg} / \mathrm{kg} \mathrm{IV} \mathrm{or} \mathrm{morphine} 0.1 \mathrm{mg} / \mathrm{kg} \mathrm{IV} \text { or } \\
\text { methadone } 0.06 \mathrm{mg} / \mathrm{kg} \mathrm{IV} \text { as premedication. } \\
\text { - Atropine } 0.005 \mathrm{mg} / \mathrm{kg} \mathrm{IV} \mathrm{included} \mathrm{in} \mathrm{premedication} \mathrm{for} \\
\text { 'some' horses. }\end{array}$ \\
\hline
\end{tabular}




\begin{tabular}{|c|c|}
\hline & 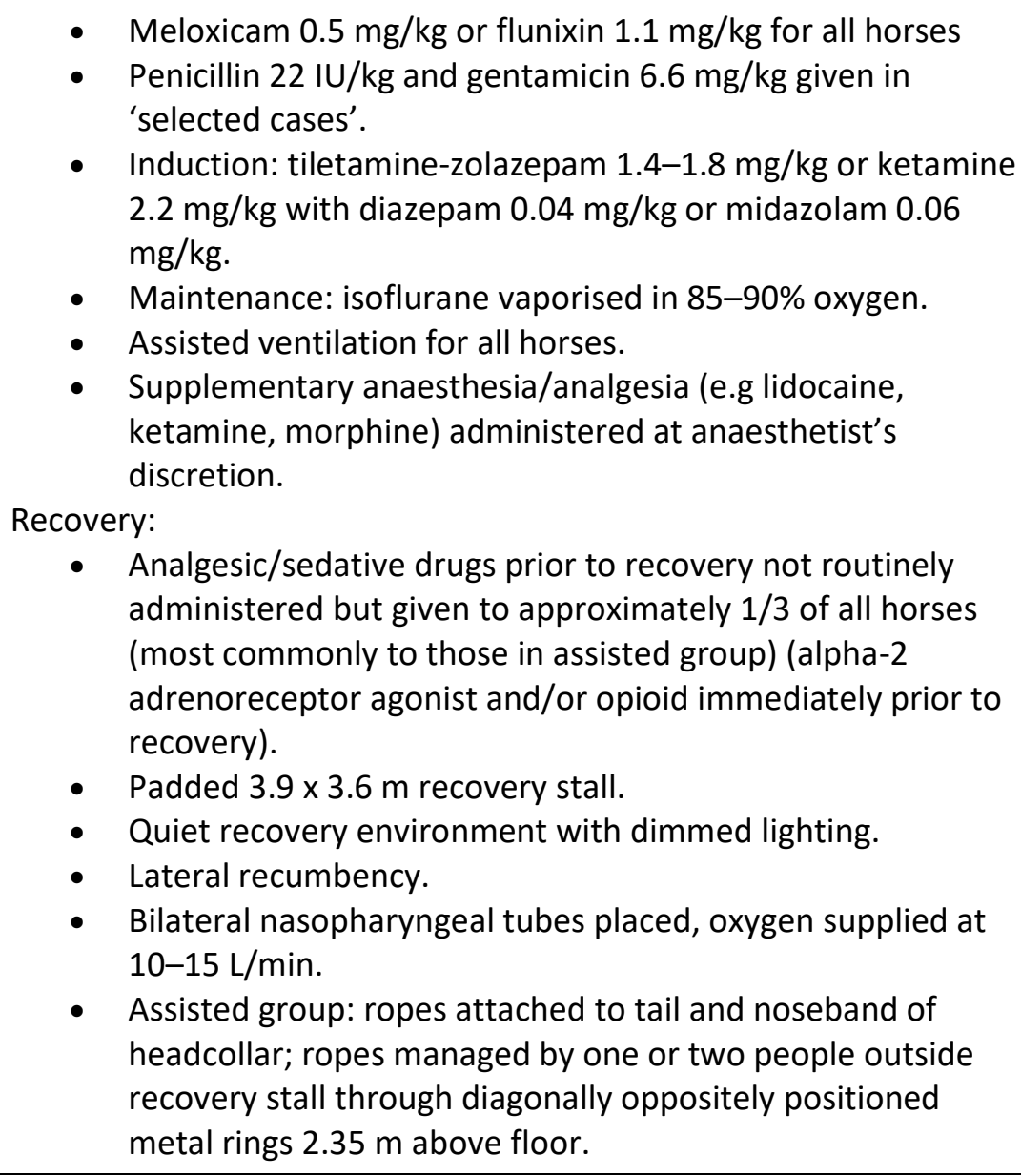 \\
\hline Study design: & Retrospective comparative analysis \\
\hline Outcome studied: & $\begin{array}{l}\text { Objective: } \\
\text { - Signalment data (breed, age, gender). } \\
\text { - Anaesthetic protocol and surgical procedure performed. } \\
\text { - } \text { Duration of anaesthesia and surgery. } \\
\text { - } \text { as nonery complications (incidence and type); type defined } \\
\text { - Mortality rates of specific procedures and recovery systems. } \\
\text { Subjective: } \\
\text { - ASA score (retrospectively assigned). } \\
\text { - Recovery score: } 0 \text { (very poor/violent recovery) to } 5 \text { (perfect } \\
\text { recovery) in assisted group only; no recovery scoring } \\
\text { performed in unassisted group. }\end{array}$ \\
\hline $\begin{array}{l}\text { Main findings: } \\
\text { (relevant to PICO question): }\end{array}$ & $\begin{array}{l}\text { - No significant difference in age, gender or body mass } \\
\text { - } \text { Oetween assisted and unassisted groups. } \\
\text { - Overall recovery complications: } 52 / 1252 \text { horses (4.2\%). } \\
\text { - Overall mortality in assisted group: } 4 / 662 \text { horses (0.6\%). } \\
\text { - Overall mortality in unassisted group: } 13 / 590 \text { horses (2.2\%) } \\
\text { Surgical procedure type (not explicitly compared between groups } \\
\text { but numbers elucidated from procedural categories data) and } \\
\text { respective recovery-associated mortality rate (this is explicitly } \\
\text { reported) }\end{array}$ \\
\hline
\end{tabular}




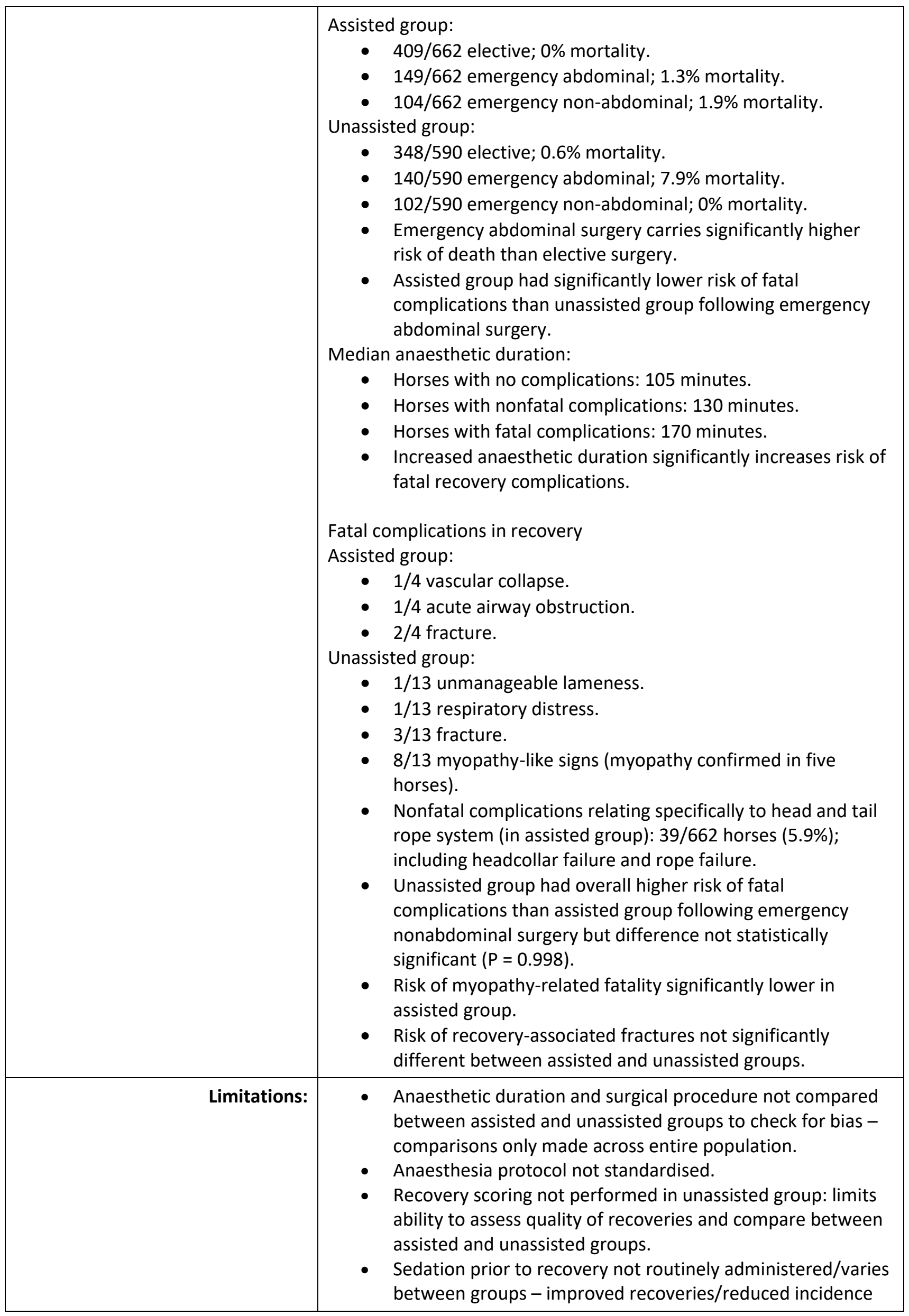




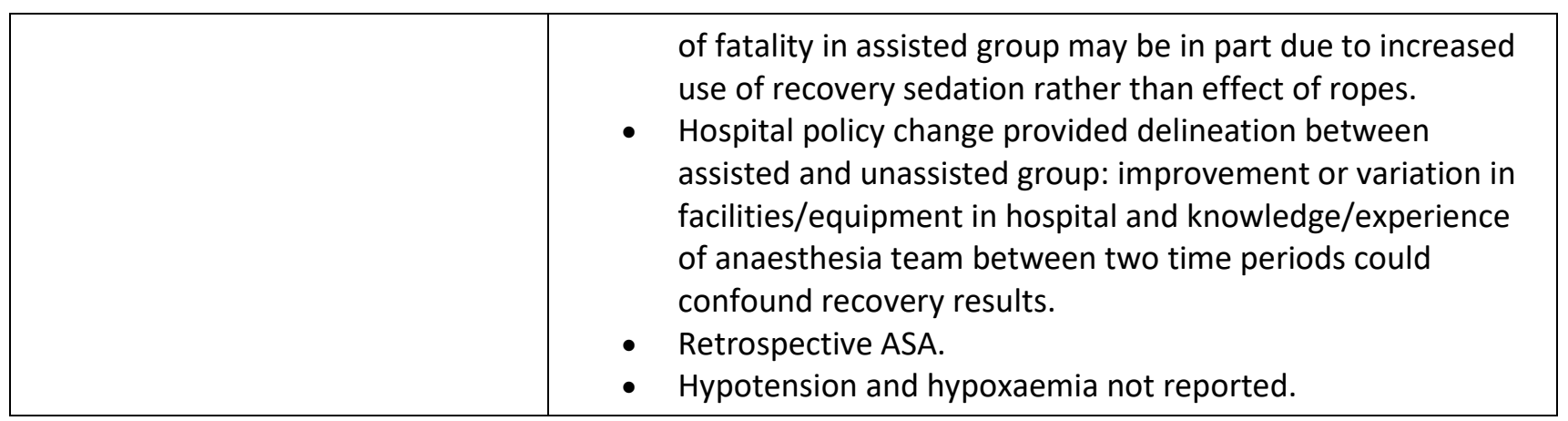

\section{Appraisal, application and reflection}

Assisting equine anaesthetic recoveries is a common practice: approximately $35 \%$ of respondents to a recently conducted questionnaire utilise head and tail ropes for horses in their clinical practice (de Miguel Garcia et al., 2021), making the critical appraisal of this intervention worthwhile. Opposing results provided by the evidence base makes it difficult to arrive at a firm conclusion regarding the utility of rope-assistance in equine anaesthesia recoveries. The findings from Rüegg et al. (2016) fail to suggest any appreciable clinical benefit of ropeassistance: there was no difference between recovery scores or timings between the assisted and unassisted groups, and several rope-associated injuries were reported. In contrast, results from Arndt et al. (2020) and Nicolaisen et al. (2020) favour rope-assistance, demonstrating significantly improved recovery quality, shorter duration of recovery and fewer attempts to stand in the rope-assisted group of Arndt et al. (2020), and a reportedly lower risk of fatal recovery complications in the assisted group of Nicolaisen et al. (2020). Duration of recovery and attempts to stand were not included in the analysis of the latter study due to inconsistencies with reporting these outcomes in the retrospective data.

It is important to consider the results of the three identified studies within the wider context of veterinary literature pertaining to the general issue of equine peri-anaesthetic morbidity and mortality. The current largest study of this subject, the Confidential Enquiry into Perioperative Equine Fatalities (CEPEF), was published in 2002 (Johnston et al., 1995; and Johnston et al., 2002), and included results from 41,824 horses undergoing general anaesthesia from 62 international clinics. Results from this analysis revealed a 1.9\% mortality rate within 7 days of anaesthesia and surgery; this decreased to $0.9 \%$ when colic cases were excluded (Johnston et al., 2002). Unfortunately, rope assistance in recovery was not evaluated in CEPEF and could be a worthwhile addition to the CEPEF study model as it begins its next round of data collection (Gozalo-Marcilla et al., 2020).

A recently published retrospective analysis of equine anaesthesia-related morbidity and mortality in one university clinic (Laurenza et al., 2020) did differentiate between assisted and unassisted recoveries in its population of 1,161 horses, but the authors 'could not observe the effect of recovery method on the risk of complication', citing the retrospective nature of the study as the reason for this. Of complications reported in this study, 92\% occurred in recovery, highlighting the need for improvements to safety in this period (Laurenza et al., 2020).

The increased risk of perioperative mortality for horses undergoing colic surgery in comparison to elective procedures is clear. The increased rate of intraoperative complications in colic cases could be expected to negatively impact recovery, potentially increasing the risk of morbidity and mortality in this period for this cohort. Perhaps this goes some way to contextualising the lack of appreciable benefit from rope assistance witnessed in the colic group in Rüegg et al. (2016). If recovery-related injury and risk of poor recovery is generally higher in these horses, rope assistance as a sole intervention may be less likely to overcome these risks completely, and clear benefits of such an intervention may therefore be difficult to demonstrate, particularly in a small population. However, for horses undergoing elective procedures, for which the expectation of a successful recovery is much higher, an opportunity is created to prevent accidental recovery complications and associated injuries, as demonstrated by Arndt et al. (2020). 
Whilst the objective outcome measures such as fatalities, time to first activity, duration of recovery and attempts to stand are easy to compare between the three identified studies, direct comparison of the numerical scores that produce the measure of 'recovery quality' is more challenging. Different scoring systems are used: a descriptive scale giving a score from 1 to 5 in both retrospective analyses offers a perhaps less nuanced method of scoring than the composite scoring system used in Arndt et al. (2020), which gives a possible score between 11 and 100. The difference between average scores was 10 for the assisted and unassisted groups in Arndt et al. (2020), but the significance of this difference is difficult to quantify in clinical terms and therefore whether it conferred a real benefit to the horses in the rope-assisted group is impossible to state with any certainty. Nicolaisen et al. (2020) did not assign recovery scores to the unassisted group, making comparisons in recovery quality impossible to deduce between the assisted and unassisted cohorts. It is also important to note that none of the scoring systems used have been validated for clinical use. The challenges of using subjective scoring measures to assess recoveries in horses, namely the lack of agreement between scorers, have been illustrated for both simple and composite scoring systems (Carter \& Anderson, 2017), highlighting the potential weakness of these systems as a qualitative outcome measure.

The influence of anaesthetic duration on recovery outcomes is an important consideration: longer anaesthetics increase the risks of recovery injuries and fatality (Johnston et al., 1995). Average anaesthetic duration was considerably shorter for the horses included in Arndt et al. (2020) (all undergoing elective procedures) than for horses in both retrospective analyses (all emergency or emergency and elective surgeries). Although anaesthetic duration did not differ significantly between assisted and unassisted groups within each individual study, the effect of duration may have been responsible for differences in recovery outcomes between study populations. This calls into question the purported positive contribution of rope assistance to producing safe recoveries in Arndt et al. (2020). Nicolaisen et al. (2020) also reinforces this relationship within its own data: median anaesthetic time was significantly longer for horses with fatal and non-fatal complications than for horses without complications, across both assisted and unassisted groups.

An interesting finding from Rüegg et al. (2016) links hypoxaemia $\left(\mathrm{PaO}_{2}<60 \mathrm{mmHg}\right)$ to an increased risk of an 'unsafe' recovery. By contrast, hypotension (defined as MAP $<70 \mathrm{mmHg}$ for $\geq 15$ minutes) was not associated with worse recoveries. This finding highlights an important limitation of Arndt et al. (2020) and Nicolaisen et al. (2020): the incidence of hypotension and hypoxaemia are not reported. The lack of this clinical information makes it difficult to be confident that differences in recovery quality between the assisted and unassisted groups in these studies can be solely attributed to rope assistance and not a reduced incidence of anaesthetic-related problems such as hypoxaemia or hypotension. It could be presumed that due to the low ASA grade of the horses in the Arndt et al. (2020) population, complications like these are less likely to occur; but they are not impossible, even in healthy horses, due to the hazards incumbent in equine anaesthesia and recumbency. Inclusion of horses undergoing emergency surgery in Nicolaisen et al. (2020) increases the likelihood of unreported hypotension and hypoxaemia. No correlation was found between hypotension or arterial blood gas tensions and recovery quality in a separate retrospective analysis of healthy horses (Young \& Taylor, 1993), but hypotension has been repeatedly linked to an increased risk of peri-anaesthetic morbidity and mortality (Laurenza et al., 2020; Young \& Taylor, 1993; and Bidwell et al., 2007), although further work is required to examine its effect on recovery quality specifically.

The inherent risks of using ropes to assist recovery are illustrated by findings from all three studies. Reported complications included detachment and twisting of ropes and, more seriously, failure of a halter ring which resulted in suspected cervical dislocation and euthanasia in one horse in Rüegg et al. (2016). Although this is a singular incident, the potential for serious problems should not be ignored when considering the use of a rope recovery system for any particular horse. Additionally, complications such as detachment and twisting of ropes would present physical risk to personnel when intervening to correct these issues. Importantly, fatalities occurred in equal numbers in both assisted and unassisted groups in Arndt et al. (2020) and Rüegg et al. (2016), illustrating the inability of rope assistance to prevent catastrophic injuries. It would seem the value of rope assistance lies in the potential improvement of quantifiable recovery variables such as shorter recovery time and fewer attempts to stand, rather than absolute prevention of fatalities. However, because of the relative infrequency of fatality in equine anaesthesia, none of the three studies have sufficient power to detect 
statistically significant differences in this outcome between groups. Therefore, rope assistance may decrease fatalities, even if it cannot completely prevent them. Although Nicolaisen et al. (2020) reports a statistically significant reduction in fatalities in the rope-assisted group, no power calculation was performed and it is likely that a larger population would be required to detect a true difference in fatality rates.

In a 2016 retrospective study from one university clinic that reported similar mortality rates to CEPEF for colic and non-colic populations ( $1.6 \%$ and $0.9 \%$ respectively), fractures were identified as the most frequent cause of recovery fatality at $71.4 \%$ (Dugdale et al., 2016). All but two of the 1,416 horses included in this study had unassisted recoveries, and the authors concluded that 'improvements to the recovery process that can reduce fracture occurrence are still required' ( Dugdale et al., 2016). The possibility for rope assistance to be one such improvement has been postulated in a review of equine anaesthesia-associated mortality (Dugdale \& Taylor, 2016), however the risk of fracture in recovery was no different between the assisted and unassisted groups in Nicolaisen et al. (2020). A much lower incidence of fracture in recovery $(0.04 \%)$ was reported by a private clinic where rope-assisted recoveries were standard protocol (Bidwell et al., 2007). However, overall mortality was also significantly lower at $0.24 \%$, so these results are likely to reflect a general difference in hospital and team circumstances (a private clinic with a high caseload of healthy horses, mostly undergoing elective orthopaedic procedures lasting under 1 hour) rather than any one specific factor. Therefore, the contribution of rope assistance to producing these results should not be overstated. The influence of the interplay between hospital and team factors here highlights the importance of individual clinic dynamics: rope assisted recoveries may be more suitable for one hospital over another, given inherent differences in teams, equipment and caseload.

Although all of the three identified studies discuss a 'traditional' one or two-person head-and-tail rope recovery system, other iterations do exist in clinical practice. A two-rope system with the tail rope under constant tension by way of a belay device was described in a retrospective analysis of rope-related complications (Niimura Del Barrio et al., 2018). The system performed well for the particular clinic involved in the study: an overall complication rate of $0.51 \%$ was reported, with very few complications directly attributed by the authors to the use of ropes (Niimura Del Barrio et al., 2018). A three-rope, two-person system, with one rope attached to either side of a headcollar and one rope attached to the tail, has been studied retrospectively and appeared to provide a 'safe recovery without any catastrophic injury' (da Silva et al., 2018). Neither of these studies, however, included a control group, and so meaningful conclusions about their utility over and above unassisted recoveries cannot be drawn.

Equine anaesthesia carries inherent risks, especially during the recovery period (Laurenza et al., 2020), and the mortality rate is much higher than that reported for small animals (Johnston et al., 2002). Ultimately, the decision to perform a rope-assisted recovery must be made considering individual patient, team and clinic factors. Taking the three identified studies and their respective weightings appointed by the hierarchy of evidence into consideration, rope assistance does appear likely to confer a benefit in the recovery of horses (sick and healthy) from general anaesthesia. However, it must be recognised that injuries can result from the use of a rope recovery system and rope assistance does not prevent catastrophic injury (including fracture) in either healthy or sick horses. Additionally, the effect of peri-operative hypotension and hypoxaemia, as well as the duration of anaesthesia, are likely to affect recovery outcome significantly, regardless of whether or not rope assistance is employed. The suitability of a rope recovery system for excitable or unhandled horses has been questioned (Niimura Del Barrio et al., 2018); the behaviour and temperament of an individual horse must be taken into account when considering an assisted recovery - but these variables are inevitably difficult to predict accurately following general anaesthesia. A 'blanket' policy of rope recovery is not recommended due to the inherent variability in the temperament of horses and capabilities and experience of personnel. 


\section{Methodology Section}

\begin{tabular}{|c|c|}
\hline \multicolumn{2}{|l|}{ Search Strategy } \\
\hline $\begin{array}{r}\text { Databases searched and dates } \\
\text { covered: }\end{array}$ & $\begin{array}{l}\text { CAB Abstracts on OVID Platform: 1973-2021 Week } 14 \\
\text { PubMed accessed via NCBI: 1920-April } 2021\end{array}$ \\
\hline Search terms: & $\begin{array}{l}\text { CAB Abstracts: } \\
\text { 1. horse* or ponies or pony or equid* or equine or gelding* or } \\
\text { mare* or stallion* or exp horses/ or exp mares/ or exp } \\
\text { stallions/ } \\
\text { 2. anaesthe* or anesthe* or exp anaesthesia/ or exp } \\
\text { anaesthetics } \\
\text { 3. rope* or roping or assist* or support* or hoist or 'head-and- } \\
\text { tail' } \\
\text { 4. unassisted or unsupported or 'free recovery' } \\
\text { Search 1: } 1 \text { and } 2 \text { and } 3 \text { and } 4 \\
\text { Search 2: } 1 \text { and } 2 \text { and ( } 3 \text { or } 4) \\
\text { PubMed: } \\
\text { 1. horse or ponies or pony or equid or equine or gelding* or } \\
\text { mare* or stallion } \\
\text { 2. anaesthesia or anesthesia or anaesthetic or anesthetic } \\
\text { 3. rope or roped or roping or assist or support or hoist or } \\
\text { 'head-and-tail' } \\
\text { 4. unassisted or unsupported or 'free recovery' } \\
\text { Search: } 1 \text { and } 2 \text { and } 3 \text { and } 4\end{array}$ \\
\hline Dates searches performed: & 14 Apr 2021 \\
\hline
\end{tabular}

\section{Exclusion / Inclusion Criteria}

\begin{tabular}{|c|c|}
\hline Exclusion: & $\begin{array}{l}\text { - } \quad \text { Not available in English. } \\
\text { - } \quad \text { Not relevant to PICO question. } \\
\text { - } \quad \text { Case repor-reviewed journal. } \\
\text { - } \quad \text { Expert opinions. } \\
\text { - } \quad \text { Book chapters/sections. }\end{array}$ \\
\hline Inclusion: & $\begin{array}{l}\text { Peer-reviewed material including retrospective and prospective } \\
\text { clinical trials and systematic reviews comparing rope assistance } \\
\text { during recovery and 'free'/unassisted recovery from general } \\
\text { anaesthesia in horses. }\end{array}$ \\
\hline
\end{tabular}




\begin{tabular}{|c|c|c|c|c|c|c|c|c|}
\hline \multicolumn{9}{|c|}{ Search Outcome } \\
\hline Database & $\begin{array}{c}\text { Number } \\
\text { of } \\
\text { results }\end{array}$ & $\begin{array}{l}\text { Excluded - } \\
\text { Irrelevant }\end{array}$ & $\begin{array}{l}\text { Excluded - Not } \\
\text { peer-reviewed }\end{array}$ & $\begin{array}{l}\text { Excluded - Case } \\
\text { report/series }\end{array}$ & $\begin{array}{l}\text { Excluded - } \\
\text { Opinion }\end{array}$ & $\begin{array}{l}\text { Excluded } \\
\text { - Book }\end{array}$ & $\begin{array}{c}\text { Excluded } \\
\text { - Not } \\
\text { English }\end{array}$ & $\begin{array}{c}\text { Total } \\
\text { relevant } \\
\text { papers }\end{array}$ \\
\hline $\begin{array}{l}\text { CAB } \\
\text { Abstracts: } \\
\text { Search } 1\end{array}$ & 6 & 3 & 1 & 0 & 1 & 0 & 0 & 1 \\
\hline $\begin{array}{l}\text { CAB } \\
\text { Abstracts: } \\
\text { Search } 2\end{array}$ & 356 & 272 & 0 & 54 & 12 & 14 & 1 & 3 \\
\hline PubMed & 13 & 12 & 0 & 0 & 0 & 0 & 0 & 1 \\
\hline \multicolumn{8}{|c|}{ Total relevant papers when duplicates removed } & 3 \\
\hline
\end{tabular}


The authors declare no conflict of interest.

\section{REFERENCES}

1. Arndt, S., Hopster, K., Sill, V., Rohn, K. \& Kästner, S.B.R. (2019). Comparison between head-tail-rope assisted and unassisted recoveries in healthy horses undergoing general anesthesia for elective surgeries. Veterinary Surgery. 49(2), 329-338. DOI: https://doi.org/10.1111/vsu.13347

2. Auer, U \& Huber, C. (2013). A comparision of head/tail rope-assisted versus unassisted recoveries of horses after patrial intravenous general anaesthesia. Abstracts presented at the Association of Veterinary Anaesthetists Spring meeting, $22^{\text {nd }}-23^{\text {rd }}$ March 2012, Davos, Switzerland. (2013). Veterinary Anaesthesia Analgesia. 40(1), 1-28. DOI: https://doi.org/10.1111/vaa.12001

3. Bidwell, L.A., Bramlage, L.R. \& Rood, W.A. (2007). Equine perioperative fatalities associated with general anaesthesia at a private practice - a retrospective case series. Veterinary Anaesthesia and Analgesia. 34(1), 23-30. DOI: https://doi.org/10.1111/j.1467-2995.2005.00283.x

4. Carter, E. \& Anderson, F. (2017). Assessment of agreement among diplomates of the American College of Veterinary Anesthesia for scoring the recovery of horses from anesthesia by use of subjective grading scales and development of a system for evaluation of the recovery of horses from anesthesia by use of accelerometry. American Journal of Veterinary Research. 78(6), 668-676.

DOI: https://doi.org/10.2460/ajvr.78.6.668

5. da Silva, D.R.P., Silva, G.B., de la Côrte, F.D., Brass, K.E., Pozzobon, R., Dau, S.L., de Gasperi, D, \& Freitas, G.C. (2018). Anesthetic recovery assisted by rope at three points in horses. Ciéncia Rural. 48(11), 1-6. DOI: http://dx.doi.org/10.1590/0103-8478cr20180154

6. de Miguel Garcia, C., Campoy, L., Parry, S., Miller, J.E., Martin-Flores, M. \& Gleed, R.D. (2021). Questionnaire on the process of recovering horses from general anesthesia and associated personnel injury in equine practice. Veterinary Anaesthesia and Analgesia. 48(2), 223-229.

DOI: https://doi.org/10.1016/j.vaa.2020.12.005

7. Dugdale, A.H., Obhrai, J. \& Cripps, P.J. (2016). Twenty years later: a single-centre, repeat retrospective analysis of equine perioperative mortality and investigation of recovery quality. Veterinary Anaesthesia and Analgesia. 43(2), 171-178. DOI: https://doi.org/10.1111/vaa.12285

8. Dugdale, A.H.A. \& Taylor, P.M. (2016). Equine anaesthesia-associated mortality: where are we now? Veterinary Anaesthesia and Analgesia. 43(3), 242-255.

DOI: http://dx.doi.org/10.1111/vaa.12372

9. Gozalo-Marcilla, M., Redondo, J.I., Johnston, M., Taylor, P. \& Bettschart-Wolfensberger, R. (2020). A new equine anaesthetic mortality study two decades after CEPEF2: CEPEF4 is going live! Equine Veterinary Journal. 52(6), 891-892. DOI: http://dx.doi.org/10.1111/evj.13327

10. Johnston, G.M., Eastment, J.K., Wood, J.L.N. \& Taylor, P.M. (2002). The confidential enquiry into perioperative equine fatalities (CEPEF): mortality results of Phases 1 and 2. Veterinary Anaesthesia and Analgesia.29(4), 159-170. DOI: https://doi.org/10.1046/j.1467-2995.2002.00106.x

11. Johnston, G.M., Taylor, P.M., Holmes, M.A. \& Wood, J.L.N. (1995). Confidential enquiry of perioperative equine fatalities (CEPEF-1): preliminary results. Equine Veterinary Journal. 27(3), 193200. DOI: http://dx.doi.org/10.1111/j.2042-3306.1995.tb03062.x

12. Laurenza, C., Ansart, L. \& Portier, K. (2020). Risk factors of anesthesia-related mortality and morbidity in one equine hospital: a retrospective study on 1,161 cases undergoing elective or emergency surgeries. Frontiers Veterinary Science. 6, 1-10. DOI: http://dx.doi.org/10.3389/fvets.2019.00514 
13. Nicolaisen, A.S.K., Bendix Nygaard, A., Christophersen, M.T., Jensen, D.B. \& Lindegaard, C. (2020). Effect of head and tail rope-assisted recovery of horses after elective and emergency surgery under general anaesthesia. Equine Veterinary Education. 1-8. DOI: https://doi.org/10.1111/eve.13397

14. Niimura Del Barrio, M.C., David, F., Hughes, J.M.L., Clifford, D., Wilderjans, H. \& Bennett, R. (2018). A retrospective report (2003-2013) of the complications associated with the use of a one-man (head and tail) rope recovery system in horses following general anaesthesia. Irish Veterinary Journal. 71(1), 1-9. DOI: http://dx.doi.org/10.1186/s13620-018-0117-1

15. Rüegg, M., Bettschart-Wolfensberger, R., Hartnack, S., Junge, H.K., Theiss, F. \& Ringer, S.K. (2016). Comparison of non-assisted versus head and tail rope-assisted recovery after emergency abdominal surgery in horses. Pferdeheilkunde. 32(5):469-478. DOI: http://dx.doi.org/10.21836/PEM20160508

16. Young, S.S. \& Taylor, P.M. (1993). Factors influencing the outcome of equine anaesthesia: a review of 1,314 cases. Equine Veterinary Journal. 25(2), 147-151. DOI: http://dx.doi.org/10.1111/i.20423306.1993.tb02926.x 


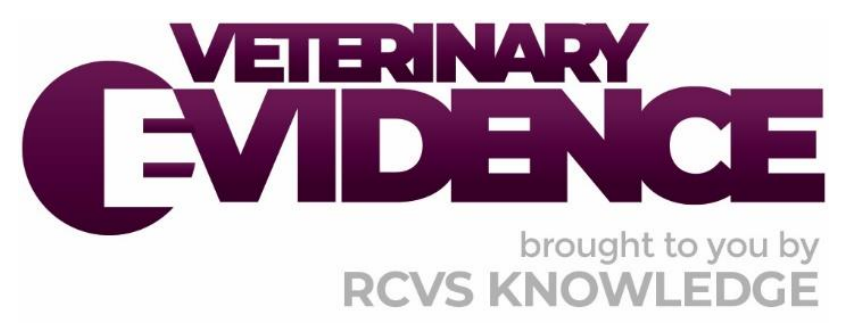

\section{Intellectual Property Rights}

Authors of Knowledge Summaries submitted to RCVS Knowledge for publication will retain copyright in their work, and will be required to grant RCVS Knowledge a non-exclusive license of the rights of copyright in the materials including but not limited to the right to publish, re-

publish, transmit, sell, distribute and otherwise use the materials in all languages and all media throughout the world, and to license or permit others to do so.

\section{Disclaimer}

Knowledge Summaries are a peer-reviewed article type which aims to answer a clinical question based on the best available current evidence. It does not override the responsibility

of the practitioner. Informed decisions should be made by considering such factors as individual clinical expertise and judgement along with patient's circumstances and owners' values. Knowledge Summaries are a resource to help inform and any opinions expressed within the Knowledge Summaries are the author's own and do not necessarily reflect the view of the RCVS Knowledge. Authors are responsible for the accuracy of the content. While the

Editor and Publisher believe that all content herein are in accord with current recommendations and practice at the time of publication, they accept no legal responsibility

for any errors or omissions, and make no warranty, express or implied, with respect to material contained within.

For further information please refer to our Terms of Use.

RCVS Knowledge is the independent charity associated with the Royal College of Veterinary Surgeons (RCVS). Our ambition is to become a global intermediary for evidence based veterinary knowledge by providing access to information that is of immediate value to practicing veterinary professionals and directly contributes to evidence based clinical decision-making.

https://www.veterinaryevidence.org/

RCVS Knowledge is a registered Charity No. 230886.

Registered as a Company limited by guarantee in England and Wales No. 598443.

Registered Office: Belgravia House, 62-64 Horseferry Road, London SW1P 2AF

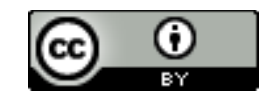

This work is licensed under a Creative Commons Attribution 4.0 International License 